VII

\title{
THE TREATMENT OF GONORRHEAL INFECTIONS BY DIATHERMY
}

\section{(With a Description of the Technique)}

By HENRY GLUCKMAN, M.R.C.S. (Eng.), L.R.C.P. (Lond.), Director Johannesburg Municipal Venereal Clinic, Lecturer on Venereal Diseases (University of the Witwatersrand).

THE object of these remarks is to record the lines along which work has been done, and the details of technique which have been elaborated as occasion arose, rather than to discuss in detail the results which have hitherto been obtained with this form of treatment.

Since February, I924, when the treatment of gonorrhœal infections by diathermy was started, some sixty patients have been treated. Although this number is far too small to permit of any definite conclusions to be drawn as to the value of this form of treatment, nevertheless certain facts have emerged, and certain lessons learnt which appear to be of sufficient interest to justify publication.

As will be seen further, throughout this period most of the time and attention have been directed towards the determination of the value of diathermy in the treatment of acute anterior gonorrhœal urethritis.

No doubt it is superfluous to mention that the diathermy treatment of gonorrhœal infections is based on the fact that the gonococcus is very susceptible to heat, and is destroyed at temperatures which are below those which damage living cells.

That this is so in vitro has been proved experimentally by different observers. Certain clinical observations suggest that in vivo the gonococcus is no less susceptible to heat. The spontaneous cures following an acute epididymo-orchitis, or an acute prostatitis, with a temperature of $103^{\circ} \mathrm{F}$. persisting for some hours, and the disappearance of gonococci after an intercurrent febrile illness, such as influenza or pneumonia, are phenomena 


\section{TREATMENT OF GONORRHGEL INFECTIONS}

which are frequently found recorded and occasionally observed in one's own practice. They would seem to be due to the lethal effect of heat on the gonococci in the tissues.

The temperature and the duration of its application which will kill gonococci in vitro varies somewhat according to different workers. Thus Luys states that " twelve hours at $39^{\circ} \mathrm{C}$. $\left(\right.$ IO $\left.2 \cdot 3^{\circ} \mathrm{F}\right)$, or six hours at $40^{\circ} \mathrm{C}$. (IO $4^{\circ} \mathrm{F}$.), are sufficient to kill it." On the other hand Corbus and O'Conor state that " it has frequently been demonstrated that the gonococcus is instantly destroyed at a temperature of $\operatorname{II} 3^{\circ} \mathrm{F} .\left(45^{\circ} \mathrm{C}\right.$.), or at $104^{\circ} \mathrm{F}$. $\left(40^{\circ} \mathrm{C}\right.$.), prolonged for six or eight hours." The same observers remark, further, "that, where the gonococci can be localised in the tissues, an exposure to $108^{\circ} \mathrm{F}$. $(42 \cdot 3 \mathrm{C}$.) will destroy them in thirty or forty minutes."

From one's own experience it has been learnt that an exposure to much higher temperatures $\left(43.5^{\circ} \mathrm{C}\right.$.) over a longer period (up to an hour) has frequently failed to affect the gonococcus, as judged clinically.

The following table, based upon bacteriological researches and other well-known figures, gives the time of exposure to different temperatures required to kill gonococci ; it has been employed as a guide to the treatments given :-

\begin{tabular}{|c|c|c|c|c|}
\hline \multicolumn{5}{|c|}{ At $4 \mathrm{I}^{\circ} \mathrm{C}$. in 3 hours $\mathrm{I} 5$ minute } \\
\hline, $42^{\circ} \mathrm{C}$ & & hour & 57 & 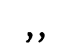 \\
\hline $80^{\circ} \mathrm{C}$ &,,$I$ & ," & I6 & \\
\hline & , I & ," & 0 & \\
\hline $44^{\circ} 5^{\circ} \mathrm{C}$. & , 0 & ," & 54 & $"$ \\
\hline & , 0 & ," & 37 & ", \\
\hline & ", 0 & $"$ & 26 & \\
\hline
\end{tabular}

Attempts to treat gonorrhœa by the application of heat were made long before diathermy came into vogue. Electrically-heated bougies and the circulation of hot water through the urethra were two of the methods tried and discarded. The reason for failure by these means was due to the fact that only very superficial heating effects could be obtained.

When by diathermy apparatus it became possible to produce heat deep down in the tissues, the idea arose of utilising this in the treatment of gonorrhœa. 


\section{BRITISH JOURNAL . OF .VENEREAL DISEASES}

\section{Diathermy in the Treatment of Acute Anterior GONORRHEAL URETHRITIS}

From the start, with this form of treatment, one feature stood out prominently and made a strong impression. It was felt that, if the favourable results obtained by those working with diathermy in gonorrhœal complications: such as prostatitis, epididymitis, arthritis, etc., were due solely, or even in part, to the direct effect of heat on the gonococcus, then the most striking success should have

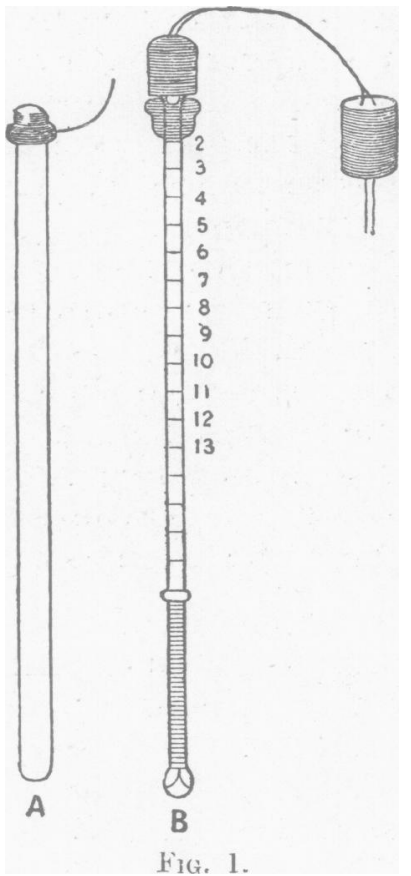

been obtained in the treatment of early limited infection of the male urethra.

It was soon realised, however, that before the treatment of this condition by diathermy could even be attempted, two essentials had to be provided, namely, a suitable electrode and a suitable temperature-measuring device whereby the temperature at all points of the urethral canal could be accurately and quickly registered during the entire sitting. It was obvious that the measurement of the applied current alone was insufficient, since, owing to the varying constitution of the individual, the same current does not produce the same rise of temperature in 


\section{TREATMENT OF GONORRHEAL INFECTIONS}

different individuals. The sensibility to heat of the patient is also no measure, as different individuals have different sensibilities to heat.

The electrode and temperature-measuring device about to be described were supplied by Siemens, who also manufactured, according to specifications, the temperature-

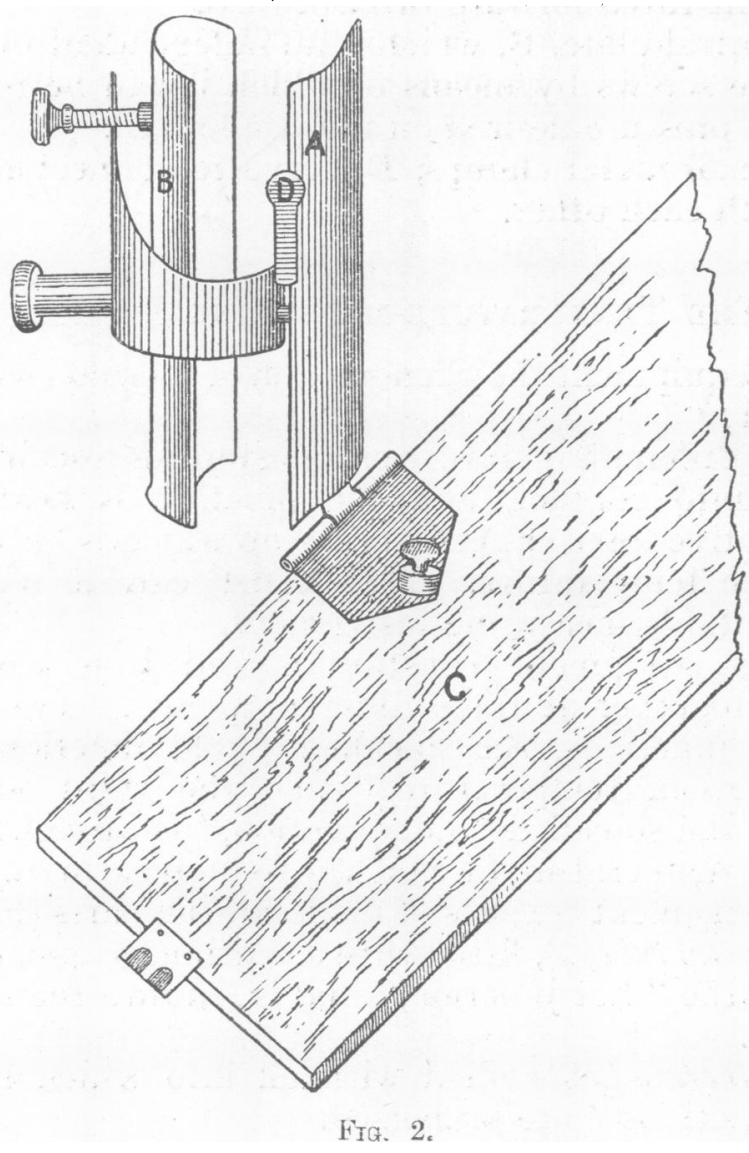

measuring prostatic and cervical electrodes and the special stand which will be referred to later.

The Electrode consists of the following parts :-

(a) The Urethral Electrode (Fig. IA). This is a straight thin-walled metal tube which is introduced into the anterior urethra and acts as the active electrode.

(b) A specially shaped Outer Electrode (Fig. 2). This consists of two metal plates $9 \mathrm{~cm}$. long, and so hollowed 


\section{BRITISH JOURNAL OF VENEREAL DISEASES}

out as to surround the penis completely. Of these plates the dorsal one, A, is fixed by means of a hinge-joint to a square ebonite support, $\mathrm{C}$, which lies, during the treatment, over the pubic region. A belt attached to this plate, and going around the body, serves to keep it fixed. By means of various screw adjustments this dorsal plate can be either raised or lowered, and through its hinge attachment tilted forward or backward.

The ventral plate, $B$, which is an independent unit, has adjustable screws by means of which it can be made to exert any pressure desired on the penile wall.

Two small metal clamps, $\mathrm{D}$, serve to connect the two plates with each other.

\section{The Temperature-measuring Device}

In this equipment the phenomenon of thermo-electricity is utilised :

If two different metals, e.g., constantan and iron, are brought into contact, and the junction is heated, an electromotive force (E.M.F.) is set up which is higher, the higher the temperature. This E.M.F can be measured with a suitable measuring instrument.

In this equipment constantan and iron wires are soldered together at three different points. Two of the soldering junctions, the so-called " cold junctions," are kept at room temperature, while the third soldering junction, the so-called " hot junction," is brought to the point the temperature of which is to be measured.

The instrument consists of the following parts (Fig. I) -

(a) A metal tube, $\mathrm{B}$, fitted with a centimetre gauge which harbours the " hot junction," and is led into the urethral electrode.

(b) A thermo-bottle filled with oil into which the two " cold junctions " are immersed.

(c) A mercury thermometer for measuring the temperature of the oil contained in the thermo-bottle.

(d) A measuring-instrument (with moving coil and with ribbon suspension). The scale of this instrument has a range from $0^{\circ} \mathrm{C}$. to $60^{\circ} \mathrm{C}$, and along it moves a very delicate pointer. The figures indicate in Celsius degrees the temperature of that part which is in contact with the "hot junction," and consequently with the urethral electrode. It is furnished also with a spirit level and with 


\section{TREATMENT OF GONORRHEAL INFECTIONS}

a movable disc by means of which it is possible to adjust the pointer so that the instrument indicates the same temperature as the thermometer in the thermo-bottle.

Connections :-

(I) Two leads connect the urethral and outer electrodes respectively to a resistance switchboard.

(2) Two leads go from the switchboard to the diathermy machine.

(3) Two small leads connect the measuring instrument to the thermo-bottle.

(4) One lead with plug and socket connect the leads from the " cold junctions" (in thermo-bottle) with that from the "hot junction" (sound inside urethral electrode).

From the description of the electrode it is obvious that by means of it an infection limited to the pendulous urethra only can be treated. In these circumstances only can the plates forming the outer electrode be kept parallel to each other and to the urethral electrode in the canal, and consequently a fairly uniform temperature obtained along the whole area treated. Once the infection has spread to the bulbous urethra, in spite of the fact that the straight urethral electrode is long enough to be inserted as far as the sphincter, no great heating can be obtained in the 3 or $4 \mathrm{~cm}$. of urethra distal to that surrounded by the plates (i.e., in the bulbous urethra). Readings such as follow are obtained :-

\begin{tabular}{|c|c|c|c|c|c|}
\hline At & I2 & $\mathrm{n}$ & t & & $39^{\circ} 2^{\circ} \mathrm{C}$. \\
\hline ," & II & ," & ," & ", & $39^{\circ} 6^{\circ} \mathrm{C}$ \\
\hline ," & IO & ," & , & ," & $40 \cdot 6^{\circ} \mathrm{C}$ \\
\hline ," & 9 & ," & ,, & ," & $42 \cdot 7^{\circ} \mathrm{C}$ \\
\hline , & 8 & ," & ," & ", & $42 \cdot 9^{\circ} \mathrm{C}$ \\
\hline , & 7 & ,, & ," & , & $43^{\circ} \mathrm{I}^{\circ} \mathrm{C}$. \\
\hline$"$ & 6 & ", & ," & ", & $43^{\circ} 2^{\circ} \mathrm{C}$ \\
\hline " & 5 & "' & ," & ," & $43.4 \mathrm{c}$ \\
\hline ", & 4 & ," & ', & $"$ & $42 \cdot 8^{\circ} \mathrm{C}$ \\
\hline " & 3 & '. & ," & ,. & $42 \cdot 6^{\circ} \mathrm{C}$ \\
\hline "я & 2 & ", & ", & ", & $42 \cdot \mathrm{I} C$ \\
\hline & I & ," & ," & ", & $42 \cdot I C$. \\
\hline
\end{tabular}

An attempt to overcome this difficulty was made by using a specially constructed ventral plate, $12 \mathrm{~cm}$. long, instead of $9 \mathrm{~cm}$. This was, however, discarded on account 


\section{BRITISH JOURNAL OF VENEREAL DISEASES}

of the fact that the inferior border of such a plate pressed deeply into the scrotal tissues and the liability of getting a burn at this point was considerable. A further attempt. to overcome this was made by inserting the urethral electrode up to the sphincter by using the ordinary $9-\mathrm{cm}$. plates, and in addition to this a perineal electrode. This helped very little. It was found that the urethral canal in the region of the tip of the urethral electrode (about $12 \mathrm{~cm}$. from the meatus), being nearest the perineal electrode, registered a very high temperature $\left(44.5^{\circ} \mathrm{C}\right.$.) ; for 2 or $3 \mathrm{~cm}$. proximal to this point the temperature dropped so much as to render the effect useless $\left(40 \cdot 8^{\circ}\right.$ to $4 \mathrm{I} \cdot 2^{\circ} \mathrm{C}$.), and it rose again only when that part of the canal was reached which was surrounded by the plates. From this point forwards it kept fairly uniform throughout the rest of the canal.

These results made it clear that, for the treatment of an infection which had reached the bulbous urethra, it would be necessary to employ the equipment which is used in treating the posterior urethra.

The second technical'difficulty encountered in the treatment of an anterior infection is shown by the following reading :-

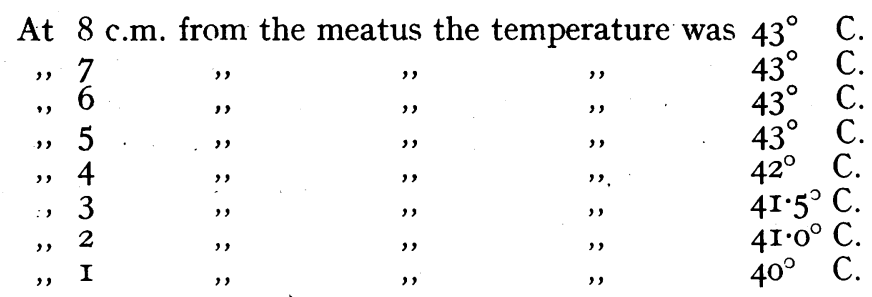

From the above it is seen that the first 4 or $5 \mathrm{~cm}$. of the urethra are at the lowest temperature-a very serious drawback, for it is in this first part of the canal that the maximum heat is required. This is due to the fact that the glans penis, beginning at the corona, tapers gradually until at the tip it is a mere point; and as the plates forming the penile electrode are parallel, it follows that the worst contact, and consequently the least heating effect, is obtained in the first few centimetres of the urethra. This was successfully overcome by wrapping the terminal 3 or $4 \mathrm{~cm}$. of the penis in layers of gauze soaked in saline and so rolled that the space which otherwise 


\section{TREATMENT OF GONORRHEAI. INFECTIONS}

exists between the tapering glans and the parallel plates is filled up. In this way the following reading was obtained :-

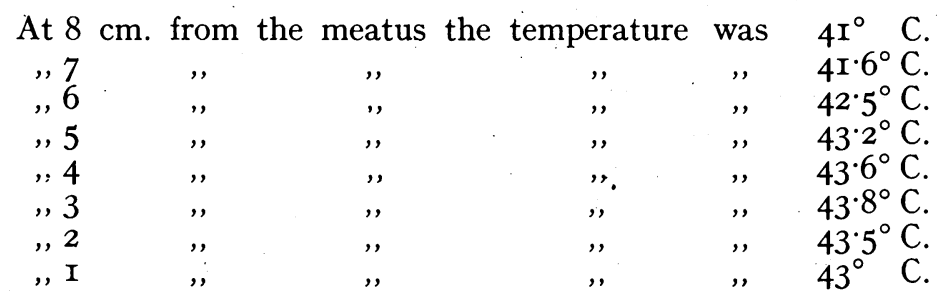

Having overcome these technical difficulties, one set about to discover the duration of the treatment which would give the most satisfactory results.

The success reported by the workers in gonorrhœal cervicitis with short (ten minutes) treatment frequently repeated encouraged the attempt of a similar procedure in this condition. Accordingly a number of patients were given daily treatments lasting twenty to thirty minutes with a mean temperature between $42^{\circ}$ to $43^{\circ}$. The greatest number of treatments given to any one case was eight. Except in two cases, where the discharge stopped for a time after two such treatments (and this might well have been due to the anterior irrigations, which were given as a routine immediately before and after each treatment), no success was obtained, and this procedure was abandoned. It was next decided to give a treatment for such a period and temperature as the most conservative figures claim to be lethal to gonococci in vitro. Accordingly several patients were given sittings lasting an hour and a half with a mean temperature of $43^{\circ} \mathrm{C}$. The results were uniformly unsuccessful.

The fact that patients found these long sittings rather trying decided one to attempt shortening the sittings and raising the temperature. But, as very few patients were found who could tolerate a temperature of $45^{\circ} \mathrm{C}$. for more than a few minutes, it became obvious that some anæsthetic, either local or general, would be necessary before such a procedure could be adopted. It was realised, however, that before an anæsthetic could be employed (either local or general) with safety, two facts had to be definitely established. These were, firstly, a complete confidence in the constant accuracy of the temperature- 


\section{BRITISH JOURNAL OF VENEREAL DISEASES}

measuring device, and secondly, the temperatures at which living tissue cells are injured.

The first factor was established as a result of the constant use of this equipment, and of the numerous experiments whereby the temperature-measuring device was tested against different types of delicate thermometers, and never found wanting.

The following remarks by Corbus and O'Conor helped one in connection with the second factor: "The normally nourished epithelial cells can survive a temperature of $\operatorname{II} 8^{\circ} \mathrm{F}$. $\left(47^{\circ} 8^{\circ} \mathrm{C}\right.$.) to $120^{\circ} \mathrm{F}$. $\left(49^{\circ} \mathrm{C}\right.$.) for one hour or more, and connective tissue cells are resistant to longer periods of heat at an elevation of more than $122^{\circ} \mathrm{F}$. $\left(50^{\circ} \mathrm{C}\right.$.)."

At first a local anæsthetic was employed in the form of 2 per cent. solution of novocain-supranin. This was first tried on healthy urethras, when it was found that a treatment lasting twenty to thirty minutes with a mean temperature of 46 to $46 \cdot 5^{\circ} \mathrm{C}$. was well tolerated.

In the inflamed urethra, however, the result was quite different. Here neither could the temperature be raised much above $44^{\circ} \mathrm{C}$., nor could the treatment be prolonged for anything like a reasonable time without the patient complaining of pain.

With local anæsthesia as an established failure, general anæsthesia was resorted to. Without going into details, it can here be stated that even with a perfect temperaturemeasuring device, and a reasonably low temperature $\left(46^{\circ} \mathrm{C}\right.$.), such a procedure is fraught with danger. The factor which comes into play rendering this method unsafe is not the high temperature, for this can be accurately measured and controlled, but the varying contact which the penile electrode makes with the penis-this is a factor which can neither be measured nor controlled by any means other than the patient's own sensations. Disheartened by these efforts, one went back to the other extreme, and decided on a very long sitting (two and a half hours) with a comparatively low temperature $\left(42^{\circ} \mathrm{C}\right.$. $)$. Strange as it may seem, the very first case so treated proved to be an unqualified success, and still stands alone as the only real success so far achieved in the acute infections of the anterior urethra.

A detailed description of this case might be of some interest. 


\section{TREATMENT OF GONORRHCEAL INFECTIONS}

Notes on a CASE OF ACUTE ANTERIOR GoNorRheAL Urethritis CUREd by a Single Treatment With Diathermy ( $2 \frac{1}{2}$ Hours)

Mr. C. P., aged 4I, was first seen at 3.I 5 p.m. on Friday, November 2oth, I925. He gave a history of exposure to infection on November I5th, I925, and also about a month previous to this. He stated that at mid-day on Thursday - twenty-seven hours previously-he noticed some intraurethral irritation; and that about mid-day on Friday, when he had passed urine, i.e., three hours before he was seen, he had noticed a " small amount of discharge." On examination the meatal lips were red, slightly odematous and glued together. When they were separated a blob, the size of a match-head, of thick yellow pus presented. This was stained by Gram's method, and on examination was found to consist of numerous pus cells, many of which were crowded with intra-cellular diplococci indistinguishable from gonococci.

The patient was given an anterior irrigation with a weak solution of boracic acid lotion, until the washings came away clear. About one and a half pints of wash were used. He then urinated. The urine was perfectly clear of haze or threads.

By 4.I5 p.m. all the connections had been completed, and the diathermy treatment started. The electrode and temperature-measuring device described were used.

The following are readings taken at different times during the sitting :-

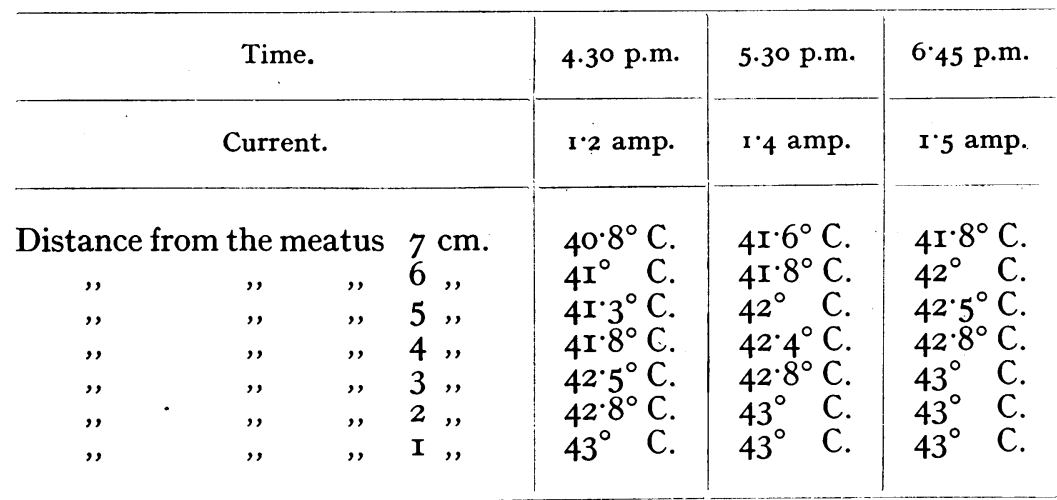

At 6.45 p.m. the treatment was stopped, the sitting having lasted for two and a half hours. The patient found the 


\section{BRITISH JOURNAL OF VENEREAL DISEASES}

treatment very trying, not from any pain experienced, but from the great discomfort of lying for such a long time in one position.

When the urethral electrode was removed, a small quantity of thin sero-hæmorrhagic fluid issued from the meatus. This was found to contain many pus cells and a great number of epithelial cells, but no gonococci could be seen. Another copious anterior irrigation with boric lotion was given, and the patient instructed to take plenty of fluids, but on no account to have any other treatment, either local or general.

The subsequent history is as follows:-

Saturday, November 2Ist.- - The patient stated that there was pain on micturition for twelve hours after the treatment. Lips glued. Small amount of serous discharge containing pus cells and epithelial cells. No gonococci.

Sunday, November 22nd.-Lips glued, a little watery discharge containing a few pus cells and a number of epithelial cells.

Tuesday, November 24th.-Lips not glued, not enough discharge to make a smear. Patient given a provocative injection of gonorrhœal vaccine and told to take alcohol.

Friday, November 27th.-No sign of discharge. Urethroscopically nothing abnormal was observed except perhaps that the mucosa appeared a little more hyperæmic than normally.

The patient has been seen repeatedly since then, and has passed all tests of cure.

Greatly encouraged by this result, I subjected three other patients, all suffering from acute anterior gonorrhœal urethritis, to the same treatment. In every case the technique employed was identical with that used in the successful case, both as regards time, temperature and application of electrodes. In each of these cases gonococci were seen in the smears taken immediately after the treatment, and not a single one of them derived any benefit. It is noteworthy, however, as a possible cause of failure, that not one of these patients was given the diathermy treatment less than fifteen hours after the discharge was first seen. If, as the above experience suggests, the time which elapses between the appearance of discharge and the giving of the treatment is the all-important factor determining success or failure, one must assume that the multiplication of the gonococcus and its extension along 


\section{TREATMENT OF GONORRHCEL INFECTIONS}

the urethral canal are much more rapid than one has hitherto been led to believe.

On the assumption, then, that these failures were due to the fact that by the time the treatment was given the gonococci had reached a region in the urethra beyond that affected by the treatment, subsequent attempts were naturally directed towards heating the whole of the urethral canal. This meant using a curved urethral sound (Fig. 3) as the active electrode, and a much more complicated equipment than the preceding. It consists not only of the two plates forming the penile electrode already described, but in addition has a horse-shoe-shaped sheet of lead foil which covers the lower portion of the abdomen and the upper portion of the groins, and a specially shaped metal instrument which fits accurately the perineum. By means of this equipment, and by varying the resistances which are interposed in the

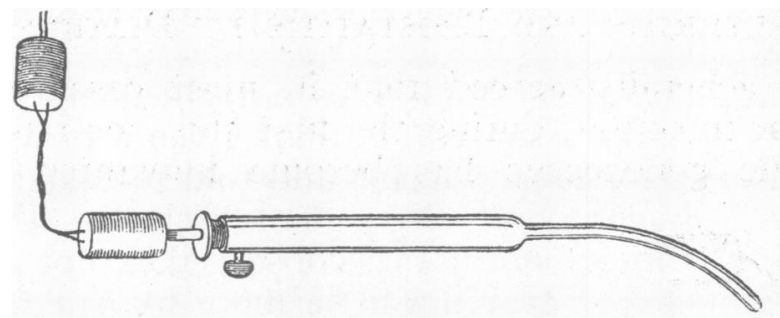

FIG. 3.

circuits responsible for heating the anterior and posterior urethra respectively, one is able to get a very uniform distribution of heat along the whole urethral canal. Thus :-

At $I 5 \mathrm{~cm}$. from the meatus the temperature was $43^{\circ} \mathrm{C}$.

\begin{tabular}{|c|c|c|c|c|c|}
\hline & & & & & \\
\hline , I4 & $"$ & $"$ & " & " & $43^{\circ} \mathrm{I}^{\circ} \mathrm{C}$ \\
\hline , I3 & ", & ," & ", & ", & \\
\hline , I2 & ," & " . & ", & ," & $43^{\circ} 5^{\circ} \mathrm{C}$ \\
\hline , II & ," & ," & ", & , & $43^{\cdot} 8^{\circ}$ \\
\hline , IO & , & , & , & , & $44^{\circ} \mathrm{I}^{\circ}$ \\
\hline & $"$ & $"$ & , & ," & $43^{\circ} 9^{\circ}$ \\
\hline ", & ", & $"$. & ", & ", & $43^{\circ} 7^{\circ}$ \\
\hline & ", & $"$ & ," & ", & $43^{\circ} 7^{\circ}$ \\
\hline & ", & ", & ", & ", & $43^{\circ} 8^{\circ}$ \\
\hline & " & ," & " & ", & 43.9 \\
\hline & " & $"$ & " & " & $44^{\circ}$ \\
\hline & $"$ & " & " & " & $44^{\circ}$ \\
\hline ", & " & " & " & " & $44^{\circ}$ \\
\hline ", & " & ", & ", & " & $44^{\circ}$ \\
\hline , & " & ", & ", & ", & $44^{\circ} 2^{\circ}$ \\
\hline
\end{tabular}




\section{BRITISH JOURNAL OF VENEREAL DISEASES}

This procedure is, however, open to very serious objections. If employed in the treatment of an anterior infection, the passage of the curved sound through an infected anterior urethra into an uninfected posterior canal almost invariably results in the infection of the latter, and this in spite of a preliminary copious anterior and subsequent posterior irrigations. Again, if employed in the treatment of an already infected posterior urethra, metastatic complications are seriously courted. Such a procedure would be justifiable only if one could completely destroy by one such treatment every gonococcus wherever situated. There is, however, an indirect method by means of which one can treat a posterior urethral infection, with or without a coincident prostatitis or vesiculitis, which is free from these objections.

\section{Treatment of Acute Posterior Gonorrhceal Urethritis AND Prostatitis By Diathermy}

It is generally agreed that in most cases of acute posterior infection, during the first three or four weeks after the gonococcus has become implanted on the

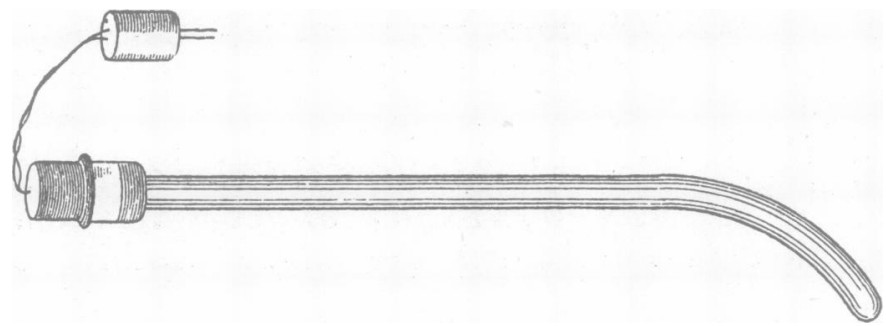

Fra. 4.

absorptive mucous membrane lining the posterior urethra, a very delicate equilibrium exists between the organisms on the one hand and the tissues on the other. During this period all local treatment to the posterior urethra is contraindicated : even anterior irrigations may have to be suspended for some time. It is during this period of forced inactivity that diathermy has been found to be a very great aid. By using a thin copper belt 2 inches wide, fixed around the pelvis, as the passive electrode and a special metal sound (prostatic electrode) in the rectum as the active one, it is possible to treat the posterior urethra indirectly. The prostatic electrode (Fig. 4) has been made 


\section{TREATMENT OF GONORRHCEAL INFECTIONS}

to order. By having a canal bored along its whole length, big enough to contain the sound with the "hot junction " of the temperature-measuring device (Fig. I, B), it is possible to measure the temperature throughout the whole treatment.

The following is a typical reading :-

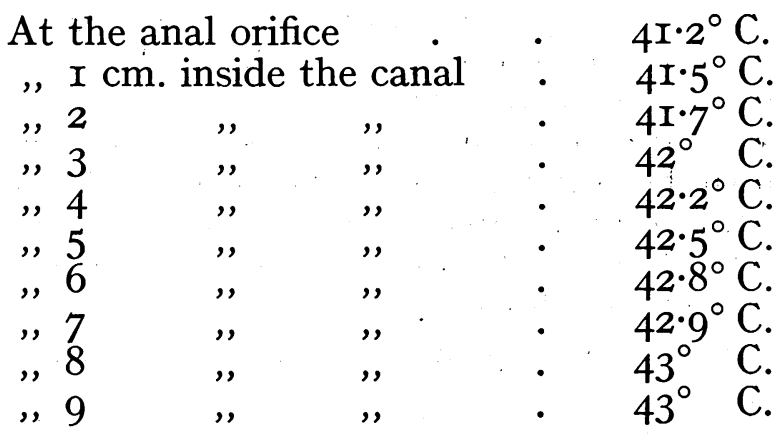

The treatments are given about twice weekly, for twenty to thirty minutes, with a mean temperature of $43^{\circ}$. C. They are unattended by any discomfort, and the results so far obtained have been encouraging. In a number of cases the symptoms subsided and the urine cleared up with four to six treatments, extending over fourteen to eighteen days. Of these patients, a few were discharged as cured after passing all tests without having had any other treatment ; others had to have, subsequent to the course of diathermy, the usual procedures of posterior irrigations, prostatic massage, etc., before they were completely freed from infection. In all cases the time taken to obtain a cure was considerably shorter than with the ordinary methods alone.

Treatments are now being given daily, and for longer periods (forty-five minutes), and it is possible that future results will be even more satisfactory.

\section{The Treatment of Gonorrheal Cervicitis BY DiATHERMY}

The cervical canal being intensive to heat, the danger of producing a burn is considerable; for here we have not even the patient's own sensation to guide us. In the absence of some suitable temperature-measuring device it became necessary to treat first the female urethra to note the dimensions of the electrode and the amount of current used, and with these as standards to work out 


\section{BRITISH JOURNAL OF VENEREAL DISEASES}

proportionately the amount of current which could be safely used with an electrode of different dimensions in the cervical canal. This seemed a very elaborate and unsatisfactory procedure. Accordingly one attempted to make a cervical elctrode with which the temperaturemeasuring device already described could be utilised. This was a simple matter; a suitable cervical electrode was obtained by altering the length and the angle of the curved portion of a small posterior male urethral electrode $\left(\frac{1}{4}\right.$ inch diameter), and by covering all but its terminal inch and a half with rubber tubing. With the uncovered part of the sound in the cervical canal, and its other end clipped in a suitable stand, and with a copper belt around the pelvis, a reading such as follows is obtained :-

Temperature at the tip of the cervical electrode (i.e., at a point)-

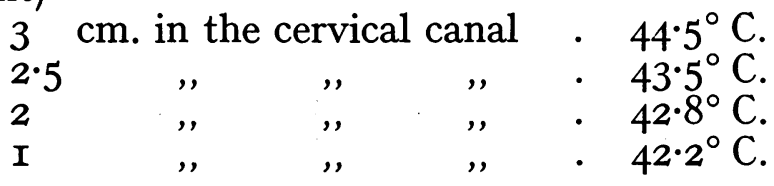

Temperature at the entrance into the cervical canal . . . . $42 \cdot 0^{\circ} \mathrm{C}$. From the above it is seen that it is difficult to obtain a uniform temperature by this method.

Temperatures of $46^{\circ} \mathrm{C}$. have been reached on many occasions without doing any harm, and without any greater complaint from the patient than a certain amount of pelvic cramp, which lasts for a few minutes and then suddenly passes off.

Although the number of cases of cervicitis treated by diathermy is far too small to justify any definite conclusions to be drawn as to its value, nevertheless it can be said that the results hitherto obtained are encouraging. Short of operative procedures, this method of treatment holds out greater promise than any other method hitherto employed in the treatment of this condition.

Diathermy in the Treatment of Sexual Impotence

It would be out of place here to discuss the different causes of premature impotence. According to Knoll, when we eliminate the cases which belong to the psychic group, and those due to some organic changes in the central nervous system, or to some constitutional dis- 


\section{TREATMENT OF GONORRHEAL INFECTIONS}

turbance, such as the different forms of anæmia, we are left with by far the biggest group which owe their existence to some localised pathological condition, i.e., to some lesion in the testicles, urethra, prostate, or seminal vesicles. In the production of impotence in this group, the verumontanum undoubtedly plays a leading rôle. Instead of the time-honoured method of treatment with silver nitrate installations, prostatic massage and the passage of cold sounds, the effect of diathermy applied to the verumontanum has been tried. This is accomplished by passing a straight gum elastic sound, until it is felt that its terminal half inch, which consists of an oliveshaped piece of metal, is through the sphincter. By gently tugging on the sound, the collar of the olive-shaped terminal can be felt to abut against the posterior surface of the triangular ligament. It is now fixed in this position. The outside end of the sound has a terminal fixed on it. This is connected by means of a lead to the diathermy machine, having a suitable resistance interposed. The copper belt is fixed around the pelvis. The patient's sensation serves as a guide to the amount of current to be used. It must frankly be admitted that it is difficult to assess the value of this form of treatment, for even in those cases with organic lesions, such as those enumerated, the psychological factor plays an imporant part, and it is consequently difficult to say how much of the limited successes obtained in these cases is due to the psychological effect of the treatment.

\section{Epididymitis, Prostatitis, Arthritis}

The technique employed in the treatment of gonorrhœal epididymitis, prostatitis and arthritis differs so little from that used by other workers that no detailed description will be attempted. In the treatment of epididymitis the Corbus electrode is used. This is a very convenient instrument which consists of a fibre clamp with curved arms, one of which is movable. This movable arm may be fastened at any desired point by means of a lock-nut. Two concave metal discs are attached to the distal ends of the arms. The entire body of the testicle and epididymus is encased between these discs. The treatments have been given daily for twenty to thirty minutes. The results have been uniformly good-the 


\section{BRITISH JOURNAL OF VENEREAL DISEASES}

pain and swelling subside more quickly than by any other means ; in a number of cases, the formation of the fibrous nodular mass in the region of the globus minor-such a common sequela in cases treated by other methods-is avoided. In connection with the treatment of chronic prostatitis and vesiculitis, nothing more need be said than that the specially constructed prostatic electrode with the temperature-measuring device is invariably used. To get any results at all, it has been found necessary to give frequent treatments of at least an hour's duration for some weeks. Then only is an improvement obtained in the vague symptoms of which these patients usually complain, and a diminution in the number of pus cells in the prostatic fluid. Only in those cases of arthritis which had been treated by the direct application of the electrodes to the joint did any benefit result. No appreciable improvement was observed in those patients in whom the primary focus (vesicles) only was treated.

\section{Vulvovaginitis}

By using a No. I8 straight urethral electrode with the temperature-measuring device, and the copper belt as the passive electrode, the following readings have been obtained :-

\begin{tabular}{|c|c|c|c|c|c|}
\hline At 8 & th & cal & & was & $40^{\circ} 5^{\circ} \mathrm{C}$. \\
\hline, 7 & ," & ," & ," & ", & $4 \mathrm{I}^{\circ} \mathrm{C}$. \\
\hline, 6 & ", & ", & ," & ", & $4 \mathrm{I} \cdot 3^{\circ} \mathrm{C}$ \\
\hline , 5 & ," & ," & ", & ", & $4 \mathrm{I}^{\circ} 5^{\circ} \mathrm{C}$ \\
\hline, 4 & , & ," & ," & ," & $4 \mathrm{I} \cdot 5^{\circ} \mathrm{C}$ \\
\hline " 3 & ", & ", & , & ", & $4 \mathrm{I} \cdot 6^{\circ} \mathrm{C}$. \\
\hline, 2 & ", & ", & , & ," & $4 \mathrm{I}^{\circ} 6^{\circ} \mathrm{C}$ \\
\hline,$I$ & ," & ," & ," & ", & $42 \quad \mathrm{C}$. \\
\hline
\end{tabular}

This form of treatment has only just been started, and it is therefore impossible to make any remarks as to its value.

\section{CoNClusion}

It is obvious that the crucial test which can determine the specific value of diathermy in the treatment of gonorrhœa is whether or not gonococci in vivo can be destroyed by it without at the same time causing damage to the tissue cells in, or on, which they are localised.

To claim that it acts specifically because pain disappears from a gonorrhœal arthritis as a result of the 264 


\section{TREATMENT OF GONORRHCEL INFECTIONS}

application of diathermy either directly to the joint or even indirectly to the primary focus, is no proof that by its means gonococci have been destroyed. The active hyperæmia of the joint resulting from the direct application, or the flooding of the circulation with the endotoxins which results from the application to the primary focus, possibly play a greater part in the production of the beneficial results than does the actual heat effect on the gonococci.

Nor can any specificity be attached to its action, because after several applications to the cervix the discharge diminishes and no gonococci can be demonstrated. The absence of gonococci in a cervical smear, even when collected with the greatest care, cannot always be accepted as a criterion of absence of infection.

Again, improvement in the symptoms in a patient suffering from chronic prostatitis is no great test-the psychological effect of the treatment is, in itself, frequently sufficient to produce this result. Nor can the absence of gonococci in the prostatic fluid be accepted as a criterionthe demonstration of gonococci in purulent prostatic fluid is a rare event in any case.

The definite presence of gonococci in the smear from a case of acute anterior gonorrhoal urethritis before a diathermy application is given, and their absence with the disappearance of all signs and symptoms after such an application without any other treatment, is the real test of this method of treatment. As already stated, this was realised from the first. The efforts made to establish the specificity, or otherwise, of this form of treatment, and the results obtained, have been described. Judged by this standard, the results have been rather disappointing. In only the case described has a cure been obtained by a single treatment with diathermy. While readily admitting the insignificance of this result, it nevertheless serves as an encouragement. One must now look for the cause of the subsequent failures. The longer time which had elapsed in these unsuccessful cases between the appearance of the discharge and the giving of the treatment cannot possibly be the whole explanation. Some other factor or factors, amongst which technique is, no doubt, an important one, must have been at work in determining these unfavourable results.

An impression is naturally gained that, in addition to 265 


\section{BRITISH JOURNAL OF VENEREAL DISEASES}

the lethal effect of heat on the gonococci, diathermy owes its beneficial effect in this condition to some other factor, about which it is possible only to theorise at present.

Although tremendous advances have been made in recent years in the diagnosis and treatment of venereal disease, a perusal of the latest text-books on the treatment of gonorrhœa shows that in this respect we are still a long way off the ideal, and this in spite of our injections and irrigations, vaccines and chemotherapeutic agents, protein shock methods and the rest.

The prevention of gonorrhœal complications can best be accomplished by a speedy and complete cure of the early urethral infection in the male. By the recognised methods of treatment, even in the most expert hands, this is still a matter fraught with uncertainty, anxiety, and only too often with disappointment. Not often is it possible to foretell with certainty in any given case of acute anterior gonorrhœal urethritis whether or not the infection will remain localised to the anterior urethra, and take three to four weeks for its cure, or whether it will spread to the posterior urethra, and take as many months. Nor is it easy to remain free from anxiety once the infection has reached the posterior urethra ; for even the cases treated under the best conditions are not free from the danger of metastatic complications, or from those resulting from direct extension.

These facts must serve as the excuse for describing a procedure which, though hitherto unattended by any very brilliant results, does nevertheless suggest the lines along which future efforts might be directed, and has a prospect of being crowned with success which is greater than that which can hitherto be claimed. 